\title{
EVALUASI EFEKTIVITAS PENERIMAAN PENDAPATAN RETRIBUSI PASAR DI DINAS KOPERASI DAN UKM KABUPATEN MINAHASA TENGGARA
}

\author{
Romario Rantetadung ${ }^{1}$, Ventje Ilat ${ }^{2}$, Winston Pontoh ${ }^{3}$ \\ 1,2,3 Jurusan Akuntansi, Fakultas Ekonomi dan Bisnis, Universitas Sam Ratulangi, Jl. Kampus Bahu, Manado \\ 95115, Indonesia
}

Email : rielrantetadung@yahoo.com

\begin{abstract}
Regional autonomy is regional empowerment in regional decision making that is more flexible to manage the resources possessed with the potential and interests of the region itself. Errors that make natural resources as the main factor in the source of regional income must be immediately changed because one day natural resources will be exhausted. The purpose of this study is to find out the process of Receiving Market Retribution in the Southeast Minahasa District Cooperative and SME Service and the effectiveness of Retribution Income at the Southeast Minahasa Regency Cooperative and SME Office. The analytical method used is descriptive qualitative. The results of the study show that the evaluation of the effectiveness of market retribution revenue at the Minahasa Regency Cooperative and SME Office in North Sumatra is quite effective. the advice given is to increase the process of collecting and depositing market retribution in the Southeast Minahasa District Government and for the Southeast Minahasa Regency government to pay more attention to the regulations issued so that the Effectiveness of Market Levy Income Revenues can achieve maximum results.
\end{abstract}

Keywords : Market retribution, department of cooperatives and smes southeast minahasa regency

\section{PENDAHULUAN}

Otonomi daerah merupakan pemberdayaan daerah dalam pengambilan keputusan daerah yang lebih leluasa untuk mengelola sumber daya yang dimiliki dengan potensi dan kepentingan daerah itu sendiri. Untuk dapat menyelenggarakan otonomi daerah yang optimal, maka diperlukan dana yang cukup. Pendapatan Asli Daerah (PAD) merupakan sumber keuangan daerah yang digali dari wilayah daerah yang bersangkutan yang terdiri dari hasil pajak daerah, hasil retribusi daerah, hasil pengelolahan kekayaan daerah yang dipisahkan dan lain-lain pendapatan asli daerah yang sah. Retribusi adalah pungutan yang dilakukan oleh pemerintah dan terdapat kontraprestasi langsung dari pemerintah. retribusi daerah adalah pungutan daerah sebagai pembayaran atas jasa atau pemberian izin tertentu yang khusus disediakan dan atau diberikan oleh pemerintah daerah untuk kepentingan orang pribadi atau badan.

\section{TINJAUAN PUSTAKA}

Konsep Akuntansi. "Lim dan Francis (2013) menyatakan bahwa akuntansi adalah suatu sistem informasi yang mengukur, memproses dan mengkomunikasikan suatu informasi keuangan mengenai entitas ekonomi. Palilingan dan Anastasia (2015) menjelaskan bahwa akuntansi adalah perangkat pengetahuan yang mempelajari perekayasaan dalam penyediaan jasa, berupa informasi keuangan dari suatu unit organisasi dan cara penyampaian (pelaporan) informasi tersebut kepada pihak yang berkepentingan".

Akuntansi Pemerintahan. "Rondonuwu dan Ritno (2015) menjelaskan bahwa akuntansi pemerintahan adalah mekanisme teknik dan analisis akuntansi yang diterapkan 
pada pengelolaan dana masyarakat, dan dijadikan informasi dalam rangka pengambilan keputusan ekonomi bagi yang memerlukan, selain itu juga meningkatkan kesejahteraan masyarakat dan bukan untuk mencari keuntungan finansial".

Konsep Akuntansi Keuangan Daerah. "Menurut Sujarweni (2015:158), definisi Akuntansi keuangan daerah adalah aktivitas jasa yang terdiri dari pencacatan, pengklasifikasian dan pelaporan transaksi ekonomi (keuangan) dari entitas pemerintah daerah (kabupaten,kota, atau provinsi) yang dijadikan sebagai informasi dalam rangka pengambilan keputusan ekonomi yang diperlukan oleh pihak-pihak eksternal entitas pemda (kabupaten, kota atau provinsi)".

Laporan Keuangan Pemerintah Daerah. "Menurut Sujarweni (2015:90), tujuan pelaporan keuangan pemerintah adalah untuk memberikan informasi yang digunakan dalam pembuatan keputusan yang menyangkut ekonomi, sosial, dan politik serta sebagai bukti pertanggungjawaban dan pengelolaan organisasi pemerintahan dan untuk memberi informasi yang akan digunakan untuk mengevaluasi kinerja manajerial dan organisasional".

Pengertian Retribusi. "Menurut Mardiasmo (2013:100), mengatakan retribusi adalah pungutan daerah sebagai pembayaran atas jasa atau pemberian izin tertentu yang khusus disediakan dan atau diberikan kepada Pemerintah Daerah untuk kepentingan orang pribadi atau badan. Retribusi Daerah yang selanjutya disebut Retribusi adalah pungutan daerah sebagai pembayaran atas jasa atau pemberian izin tertentu yang khusus disediakan dan atau diberikan oleh Pemerintah Daerah untuk kepentingan orang pribadi atau badan.

Pengertian Efektivitas. "Menurut Mahmudi (2010:143), menyatakan bahwa efektivitas merupakan hubungan antara keluaran dengan tujuan atau sasaran yang harus dicapai. Dikatakan efektif apabila proses kegiatan mencapai tujuan dan sasaran akhir kebijakan”. Retribusi pasar dapat dikategorikan tingkat efektivitasnya sebagai berikut:

Tabel 1. Kategori tingkat efektivitas

\begin{tabular}{ll}
\hline Lebih dari $100 \%$ & Sangat efektif \\
$90 \%-100 \%$ & Efektif \\
$80 \%-90 \%$ & Cukup efektif \\
$60 \%-80 \%$ & Kurang efektif \\
$60 \%$ & Tidak effektif
\end{tabular}

Sumber : Mahmudi (2010)

Penelitian Terdahulu. "Marselina (2013) Analisis Kontribusi Pajak Parkir Dan Retribusi Pasar Terhadap Pendapatan Asli Daerah Pada Pemerintah Kota Padang. Hasil penelitian ini menunjukan bahwa (1) Kontribusi pajak parkir hasilnya berfluktuatif dengan kisaran 0,01\%-0,17\%, sangat jauh dari efektif (2) Kontribusi retribusi pasar hasilnya juga berfluktuatif dari tahun ke tahun namun sudah bagus dari kontribusi pajak parkir yaitu berkisar dari 2\%-4\%, (3) Kontribusi pajak parkir terhadap pajak daerah kontribusinya dari tahun ke tahun selalu mengalami penurunan, kisaran rata-rata rasio nya berkisar 5\%-3\%. (4) Kontribusi retribusi pasar terhadap retribusi daerah sudah mulai membaik di bandingkan sebelumnya, dimana hasilnya sudah mendekati efektif dengan kisaran 11\% - 14\%". Mumiati dan Kasasih (2017) “Analisis Kontribusi Dan Efektivitas Penerimaan Retribusi Pelayanan Pasar Terhadap Pendapatan Asli Daerah Kota Palembang. Berdasarkan Tingkat efektivitas 2012 sebesar 100\% sehingga dapat dianggap efektif. Pada 2013 tingkat efektivitasnya 100\% sehingga bisa dianggap efektif. Namun, pada 2014 tingkat efektivitasnya sebesar 3,95\% sehingga bisa dianggap tidak efektif, Pada 2015 tingkat efektivitasnya 11: 18\% sehingga bisa dianggap tidak efektif". Ersita dan Elim (2016) “Analisis Efektivitas Penerimaan Retribusi Daerah Dan Kontribusinya Terhadap Peningkatan Pendapatan Asli Daerah (Pad) Di Provinsi Sulawesi Utara. Hasil penelitian adalah Tingkat efektivitas untuk retribusi daerah selama 
tahun 2011-2015 masuk dalam kategori Cukup efektif. Kontribusi retribusi daerah PAD Provinsi SULUT dari tahun 2011-2015 berkontribusi sedang tetapi rasio kontribusinya cenderung naik setiap tahunnya hanya pada tahun 2015 mengalami penurunan". Suhardoyo dan Rahayu (2018) "Optimalisasi Potensi dan Efektivitas Penerimaan Retribusi Pasar di Pasar Wage Purwokerto Kabupaten Dati II Banyumas. Hasil penelitian menunjukkan bahwa penerimaan Retribusi di Pasar Upah Purwokerto masih belum optimal menunjukkan penerimaan sebesar Rp 180.565.500,00 sedangkan berdasarkan perhitungan dengan pemrograman linier untuk mencapai hasil yang optimal menunjukkan penerimaan sebesar Rp 196.662.000,00 dengan kombinasi jenis pedagang rata-rata per hari kios 73 orang, pedagang kehilangan 389 orang dan pedagang lesehan berjumlah 350 orang. Jadi ada perbedaan pendapatan retribusi per tahun $\mathrm{Rp}$ 16.096.500,00. Sedangkan penarikan retribusi retribusi Kios pedagang dan pedagang lesehan telah dilaksanakan secara efektif karena berdasarkan perhitungan efektivitas memiliki nilai $=1$, sedangkan pelaksanaan retribusi pasar retribusi Los pedagang menunjukkan hasil yang belum efektif dengan nilai $0,86<1$ ". Rembet, Tinangon, dan Runtu (2018) "Analisis Efektivitas Penagihan Retribusi Persampahan Dan Kontribusinya Terhadap Pendapatan Asli Daerah Kota Tomohon. Hasil penerimaan efektif pungutan limbah padat pada 2015-2016 tidak efektif dan menurun, kemudian pada 2017 meskipun masih tidak efektif tetapi mengalami peningkatan yang sangat drastis. Kontribusi retribusi limbah padat terhadap retribusi daerah masih relatif kecil pada tahun 2015 dan 2016 tetapi pada tahun 2017 kontribusinya sangat signifikan terhadap retribusi daerah. Sementara kontribusi retribusi limbah padat ke PAD Kota Tomohon pada 2015-2017 sangat kecil selama 3 tahun terakhir". Saad dkk (2017) "Arrangement of the Street Parking at the Pomalaa Market of Kolaka Regency. Hasil penelitian ini menunjukkan bahwa (1) parkir di Pasar Pomalaa sangat mengganggu kelancaran lalu lintas, (2) Jalan Ekonomi yang memungkinkan digunakan untuk kendaraan parkir dengan konfigurasi paralel dan sudut 300 di satu sisi jalan, sedangkan Hati Jalan Gembira, Jalan Konggasa, dan Jalan Hati Senang hanya digunakan untuk parkir sepeda motor. (3) Manajemen parkir di Pasar Pomalaa belum optimal dan belum memenuhi target penerimaan retribusi yang telah ditetapkan".

\section{METODE PENELITIAN}

Jenis Penelitian. "Penelitian ini termasuk dalam penelitian kualitatif deskriptif. Oleh karena itu melalui penelitian deskriptif ini penulis akan memberikan gambaran mengenai Pemungutan dan Penyetoran Retribusi Pasar pada instansi pemerintah di Dinas Koperasi dan UKM Kabupaten Minahasa Tenggara".

Tempat dan Waktu Penelitian. "Penelitian ini dilakukan pada Dinas Koperasi dan UKM Kabupaten Minahasa Tenggara yang beralamatkan di Kompleks Perkantoran Blok.B, Kel.Wawali Pasan, Kec. Ratahan, Kab.Minahasa Tenggara dan waktu penelitian dilakukan pada bulan Maret 2017 sampai Mei 2018".

Jenis Data, Sumber Data dan Metode Pengumpulan Data. "Jenis data yang digunakan yaitu data kualitatif mengenai Efektifitas Pengendalian Intern atas Penerimaan Pendapatan Retribusi Pasar di Dinas Koperasi dan UKM Kabupaten Minahasa Tenggara. Menurut Kuncoro (2011:148), sumber data penelitian dibagi menjadi dua yaitu Data Primer, adalah data yang diperoleh dengan survei lapangan yang menggunakan semua metode pengumpulan data original dan Data sekunder adalah data yang telah dikumpulkan oleh lembaga pengumpul data dan dipublikasikan kepada masyarakat pengguna data. Sumber data yang digunakan ialah sumber primer dan sekunder. Teknik yang digunakan dalam pengumpulan data untuk penelitian ini adalah Teknik Dokumentasi. Teknik ini dilakukan dengan cara mendapatkan informasi dari buku-buku literature, majalah, jurnal serta bahanbahan informasi lainnya yang berhubungan dengan masalah yang diteliti". 
Metode dan Proses Analisis. Adapun metode analisis yang digunakan untuk membahas permasalahan dalam penelitian ini adalah analisis deskriptif yang akan diuraikan sebagai berikut.

1. Mengetahui dan mempelajari struktur organisasi serta tugas dan tanggungjawab yang ada pada Dinas Koperasi dan UKM Kabupaten Minahasa Tenggara.

a. Gambaran umum tentang Dinas Koperasi dan UKM Kabupaten Minahasa Tenggara.

b. Visi dan Misi Dinas Koperasi dan UKM Kabupaten Minahasa Tenggara.

c. Tugas Pokok dan Fungsi Dinas Koperasi dan UKM Kabupaten Minahasa Tenggara.

d. Struktur Organisasi Dinas Koperasi dan UKM Kabupaten Minahasa Tenggara.

2. Memperoleh gambaran umum mengenai penerimaan pendapatan retribusi pasar di Dinas Koperasi dan UKM Kabupaten Minahasa Tenggara.

a. Proses Mekanisme Pemungutan Retribusi Pasar pada Dinas Koperasi dan UKM Kabupaten Minahasa Tenggara.

b. Mekanisme Penyetoran Retribusi Pasar pada Dinas Koperasi dan UKM Kabupaten Minahasa Tenggara.

3. Mengumpulkan formulir-formulir yang berhubungan dengan penerimaan pendapatan retribusi pasar kemudian menghitung dengan rumus perhitungan efektivitas retribusi pasar. Adapun rumus yang digunakan adalah sebagai berikut.

$$
\text { Efektivitas Retribusi Pasar }=\frac{\text { Realisasi Penerimaan Retribusi Pasar }}{\text { Target Penerimaan Retribusi Pasar }} \text { X 100\% }
$$

4. Membuat pembahasan tentang Evaluasi Efektivitas penerimaan pendapatan retribusi pasar di Dinas Koperasi dan UKM Kabupaten Minahasa Tenggara serta kesimpulan dan saran dari hasil penelitian.

\section{HASIL ANALISIS DAN PEMBAHASAN}

4.1. Hasil Analisis

Administrasi Pengelolaan Penerimaan Pendapatan Retribusi Pasar, Dalam upaya penertiban tempat usaha dalam lokasi pasar, pedagang mengajukan permohonan tempat usaha kepada Kepala Dinas Koperasi dan UKM Kabupaten Minahasa Tenggara untuk mendapatkan Surat Ijin Menempati (SIM) lokasi serta sarana yang akan digunakan dalam kegiatan perdagangan. Berdasarkan surat permohonan tersebut, Dinas Koperasi dan UKM melukakan verifikasi terhadap lokasi yang dimohon guna menghindari tumpah tindih pemberian SIM kepada pedagang. Kemudian Kepala Dinas Koperasi dan UKM menerbitkan SIM kepada pemohon untuk mendapatkan ijin menempati secara legal dan dapat menempati suatu lokasi dalam pasar yang telah terdaftar. Selanjutnya Sekretaris Dinas Koperasi dan UKM serta kepala pasar melakukan pengarsipan dan pencatatan Surat Ijin Menempati dimaksud diatas untuk menjadi dasar pemungutan Retribusi Pasar. Untuk pemungutan Retribusi Pasar perlu persiapan karcis dengan dibuat prosedur sebagai berikut, karcis dibuat oleh Dinas Koperasi dan UKM, selanjutnya diserahkan ke Dinas Pendapatan Daerah untuk dilakukan perporasi sebagai tanda sah milik pemerintah daerah. Kemudian karcis yang telah diperporasi diserahkan kembali kepada Dinas Koperasi dan UKM. Saat penyerahan karcis, dibuat bukti tanda terima banyaknya karcis dan nilai yang diserahkan kepada Dinas Koperasi dan UKM.

Alur Pemungutan Retribusi Pasar. Keterangan Alur Pemungutan Retribusi Pasar adalah sebagai berikut: (1) Sekretaris Dinas Koperasi dan UKM melakukan pengarsipan dan pencatatan Surat Ijin Menempati (SIM) sebagai bukti bahwa proses administrasi telah selesai; (2) Pedagang mendapatkan SIM untuk berdagang dipasar dengan status legal dan dapat menempati suatu lokasi dalam pasar yang telah terdaftar; (3) Dinas Koperasi dan UKM 
Kabupaten Minahasa Tenggara mengambil karcis yang telah diperporasi dari Badan Keuangan Kabupaten Minahasa Tenggara, kemudian memberikan kepada bendahara penerimaan sesuai kebutuhan dengan memperhitungkan jumlah ijin menempati yang telah dikeluarkan; (4) Bendahara penerimaan menerima karcis dan akan di register atau dilakukan penghitungan berapa banyak jumlah yang masuk dalam Unit Pasar Kabupaten Minahasa Tenggara untuk diberikan pada pedagang sebagai bukti pembayaran retribusi; (5) Mandor Pasar melakukan pemungutan retribusi harian menggunakan karcis dan pemungutan dilakukan setiap hari; (6) Pedagang akan membayarkan retribusi berdasarkan tarif yang telah ditetapkan berdasarkan Peraturan Daerah Kabupaten Minahasa Tenggara Nomor 6 Tahun 2011; (7) Mandor Pasar menerima pembayaran dan memberikan karcis tanda bukti penyetoran retribusi kepada pedagang; (8) Pedagang menerima karcis yang telah diberikan oleh Mandor Pasar.

Alur Penyetoran Retribusi Pasar. Keterangan Alur Penyetoran Retribusi Pasar: (1) Bendahara Penerimaan Dinas Koperasi dan UKM menerima uang setoran retribusi pasar dari pedagang dan kelebihan karcis dari mandor pasar; (2) Bendahara penerima Dinas Koperasi dan UKM melakukan pembukuan dan rekapitulasi retribusi dalam STS (Surat Tanda Setor) rangkap 8 lembar. Kemudian STS 8 lembar ini, nantinya akan dibagi menjadi 1 lembar STS untuk arsip kantor, 2 lembar STS untuk Bendahara Dinas Koperasi dan UKM Kabupaten Minahasa Tenggara, 5 lembar STS untuk bank yang ditunjuk atau kas daerah; (3) Bendahara penerima menyetorkan jumlah uang retribusi yang dibayarkan oleh pedagang dengan melampirkan 5 lembar STS ke bank yang ditunjuk oleh Badan Keuangan Kabupaten Minahasa Tenggara, yaitu Bank SULUT; (4) Bank SULUT menerima setoran dan akan memberikan 3 lembar BS (Bukti Setor) berupa slip pembayaran kepada bendahara penerimaan sebagai bukti Pembayaran; (5) Bendahara penerima menerima 3 lembar Bukti Setor berupa slip pembayaran; (6) Bank SULUT akan mengirimkan masing-masing 1 lembar STS dan Bukti Setor ke bagian keuangan di Badan Keuangan Kabupaten Minahasa Tenggara; (7) Bagian keuangan pada Badan Keuangan Kabupaten Minahasa Tenggara menerima Surat Tanda Setor (STS) dan Bukti Setor; (8) Bank SULUT akan mengirimkan 2 lembar STS ke bagian pembukuan harian dan bagian nomor Tanda Setor Dinas Koperasi dan UKM Kabupaten Minahasa Tenggara; (9) Bagian Pembukuan harian dan bagian Nomor Tanda Setor Dinas Koperasi dan UKM Kabupaten Minahasa Tenggara menerima 2 lembar STS (Surat Tanda Setor). Berikut ini adalah tabel rekaptulasi realisasi penerimaan retribusi pasar Kabupaten Minahasa Tenggara:

Tabel 2. Rekapitulasi Realisasi Penerimaan Retribusi Pasar di Kabupaten Minahasa Tenggara

\begin{tabular}{ccc}
\hline Tahun Anggaran & $\begin{array}{c}\text { Target Penerimaan } \\
\text { Retribusi Pasar } \\
(\mathbf{R p})\end{array}$ & $\begin{array}{c}\text { Realisasi Penerimaan } \\
\text { Retribusi Pasar } \\
(\mathbf{R p})\end{array}$ \\
\hline 2012 & 120.000 .000 & 101.000 .000 \\
2013 & 110.000 .000 & 89.090 .000 \\
2014 & 115.000 .000 & 78.200 .500 \\
2015 & 110.000 .000 & 105.800 .500 \\
2016 & 125.000 .000 & 106.900 .000 \\
\hline
\end{tabular}

Sumber: Data Olahan 2018

Tabel 2 menunjukan bahwa rekapitulasi realisasi penerimaan retribusi pasar pada tahun 2012 sampai dengan 2014 mengalami penurunan realisasi penerimaan, kemudian meningkat pada tahun 2015 sampai dengan 2016. 


\subsection{Pembahasan}

Tingkat efektivitas penerimaan retribusi pasar yang pemungutannya melalui karcis pasar di Kabupaten Minahasa Tenggara, dihitung dengan membandingkan antara realisasi penerimaan retribusi pasar dengan target penerimaan retribusi pasar. Apabila perhitungan efektivitas Penerimaan Retribusi Pasar menghasilkan presentase mendekati atau melebihi 100\%, maka Penerimaan Pendapatan Retribusi Pasar efektif Dinas Koperasi dan UKM Kabupaten Minahasa Tenggara semakin baik. Tabel berikut ini menunjukan hasil perhitungan efektifitas Penerimaan Pendapatan Retribusi Pasar di Dinas Koperasi dan UKM Kabupaten Minahasa Tenggara tahun anggaran 2016.

Tabel 3. Efektivitas Penerimaan Pendapatan Retribusi Pasar di Dinas Koperasi dan UKM Kabupaten Minahasa Tenggara

\begin{tabular}{ccccc}
\hline $\begin{array}{c}\text { Tahun } \\
\text { Anggaran }\end{array}$ & $\begin{array}{c}\text { Target } \\
\text { Penerimaan } \\
\text { Retribusi Pasar } \\
(\mathbf{R p )}\end{array}$ & $\begin{array}{c}\text { Realisasi } \\
\text { Penerimaan } \\
\text { Retribusi Pasar } \\
(\mathbf{R p )}\end{array}$ & $\begin{array}{c}\text { Efektivitas } \\
\text { Retribusi } \\
\text { Pasar }\end{array}$ & $\begin{array}{c}\text { Kriteria } \\
\text { Efektivitas }\end{array}$ \\
\hline 2012 & 120.000 .000 & 101.000 .000 & $84,1 \%$ & Cukup Efektif \\
2013 & 110.000 .000 & 89.090 .000 & $80,9 \%$ & Cukup Efektif \\
2014 & 115.000 .000 & 78.200 .500 & $68 \%$ & Kurang Efektif \\
2015 & 110.000 .000 & 105.800 .500 & $96,1 \%$ & Efektif \\
2016 & 125.000 .000 & 106.900 .000 & $85,5 \%$ & Cukup Efektif \\
Rata - Rata & $\mathbf{1 1 6 . 0 0 0 . 0 0 0}$ & $\mathbf{9 6 . 1 9 8 . 2 0 0}$ & $\mathbf{8 2 , 9 \%}$ & Cukup Efektif \\
\hline
\end{tabular}

Sumber: Data Olahan 2018

Tabel 3 menunjukan bahwa efektivitas Penerimaan Pendapatan Retribusi Pasar pada dari tahun 2012 sampai dengan 2016 Cukup Efektif. sebesar 82,9 \%. Bisa dilihat bahwa dari tahun 2012 sampai dengan tahun 2014 realisasi penerimaan retribusi pasar selalu menurun setiap tahunnya dan kemudian meningkat pada tahun 2015 dengan capaian efektivitas sebesar 96,1\% realisasinya. Hal ini menunjukan bahwa manajemen dalam pengawasan Penerimaan Pendapatan Retribusi Pasar di Dinas Koperasi dan UKM Kabupaten Minahasa Tenggara cukup efektif.

\section{KESIMPULAN DAN SARAN}

\subsection{Kesimpulan}

Kesimpulan yang di ambil dari penelitian ini:

1. Penerimaan Retribusi Pasar diterima melalui prosedur sebagai berikut, karcis dibuat oleh Dinas Koperasi dan UKM, selanjutnya diserahkan ke Dinas Pendapatan Daerah untuk dilakukan perporasi sebagai tanda sah milik pemerintah daerah. Kemudian karcis yang telah diperporasi diserahkan kembali kepada Dinas Koperasi dan UKM. Saat penyerahan karcis, dibuat bukti tanda terima banyaknya karcis dan nilai yang diserahkan kepada Dinas Koperasi dan UKM.

2. Evaluasi efektivitas penerimaan pendapatan retribusi pasar dengan melihat efektivitas penerimaan pendapatan retribusi pasar di Dinas Koperasi dan UKM Kabupaten Minahasa Tenggara yang kurang dari $100 \%$ atau sebesar $82,9 \%$ hal ini menunjukan bahwa kinerja dalam pemungutan pendapatan retribusi pasar di Dinas Koperasi dan UKM Kabupaten Minahasa Tenggara cukup efektif.

\subsection{Saran}

Saran diberikan:

1. Proses pemungutan dan penyetoran retribusi pasar di Pemerintah Kabupaten Minahasa Tenggara diharapkan untuk ditingkatkan lagi. 
2. Bagi Pemerintah Kabupaten Minahasa Tenggara agar lebih memperhatikan peraturan yang dikeluarkan sehingga Efektivitas atas Penerimaan Pendapatan Retribusi Pasar bisa mencapai hasil yang lebih maksimal serta lebih memperbaiki dalam hal penulisan dan pembuatan laporan realisasi anggaran pendapatan dan belanja daerah.

\section{DAFTAR PUSTAKA}

Ersita, M dan Elim, I (2016) Analisis Efektivitas Penerimaan Retribusi Daerah Dan Kontribusinya Terhadap Peningkatan Pendapatan Asli Daerah (Pad) Di Provinsi Sulawesi Utara. Jurnal Going Concern. http:// ejournal.unsrat.ac.id. Diakses Tanggal 10/01/2019.

Kuncoro, M. (2011), Metode Riset Untuk Bisnis dan Ekonomi Bagaimana Meneliti dan Menulis Tesis?, Edisi 3, Jakarta: Erlangga.

Lim dan Francis Pol C. 2013. "Impact of Information Technology on Accounting Systems".Asia-PasificJornal of Multimedia Services Convergent with Art, Humanities and Socialgy, Vol 3 No 2.ISSN : 2383-5281. Hal 93-106. http://www.sersc.org/journals/AJMAHS/vol3_no2_2013/6.pdf.

Mahmudi (2010) Manajemen Kinerja Sektor Publik. Edisi 2. Yogyakarta: UPP STIM. YKPN,.

Mardiasmo (2013) Akuntansi Sektor Publik. Yogyakarta: Andi.

Marselina, E (2013) Analisis Kontribusi Pajak Parkir Dan Retribusi Pasar Terhadap Pendapatan Asli Daerah Pada Pemerintah Kota Padang. Jurnal Ekonomi. http://www.sersc.org/journals Diakses Tanggal 22/04/2018

Muniarti, S dan Kasasih, D (2017) Analisis Kontribusi Dan Efektivitas Penerimaan Retribusi Pelayanan Pasar Terhadap Pendapatan Asli Daerah Kota Palembang. Jurnal kompetitif. Vol 6 No.1. http://www.sersc.org/journals Diakses Tanggal 22/04/2018.

Palilingan dan Anastasia (2015) Analisis Kinerja Belanja Dalam Laporan Realisasi Anggaran (Lra) Pada Dinas Pendapatan Kota Manado. Skripsi Universitas Sam Ratulangi Manado.Vol. 3, No. 1.

Rembet. E, Tinangon. J, dan Runtu. T (2018) Analisis Efektivitas Penagihan Retribusi Persampahan Dan Kontribusinya Terhadap Pendapatan Asli Daerah Kota Tomohon. Jurnal Going Concern. http:// ejournal.unsrat.ac.id. Diakses Tanggal 10/01/2019.

Rondonuwu, Ritno (2015) Analisis Efisiensi Dan Efektivitas Pengelolaan Keuangan Daerah Pada Dinas Pendapatan Daerah Kabupaten Minahasa. Jurnal Going Concern. http:// ejournal.unsrat.ac.id. Diakses Tanggal 10/01/2019.

Saad, S, R, dkk (2017) Arrangement of the Street Parking at the Pomalaa Market of Kolaka Regency. International Journal of Engineering Inventions. Volume 6, Issue 5. www.ijeijournal.com. Diakses Tanggal 22/04/2018.

Suhardoyo dan Rahayu, E, I, H (2018) Optimalisasi Potensi dan Efektivitas Penerimaan Retribusi Pasar di Pasar Wage Purwokerto Kabupaten Dati II Banyumas. Widya Cipta. Vol II No.1. www.ijeijournal.com Diakses Tanggal 22/04/2018.

Sujarweni (2015) Akuntansi Keungan. Yogyakarta : Pustaka Baru Press 